\title{
The Local Wisdom Management Mohom for Stable Inherit and Lifelong Learning
}

\author{
Nawatrot Intem ${ }^{1}$, Thongchai Phuwanatwichit ${ }^{2}$, Atchara Sarobol ${ }^{2} \&$ Chetthapoom Wannapaisan $^{1}$ \\ ${ }^{1}$ Faculty of Education, Chiang Mai University, Thailand \\ ${ }^{2}$ Faculty of Humanities, Chiang Mai University, Thailand \\ Correspondence: Nawatrot Intem, Faculty of Education, Chiang Mai University. 239 Huay Kaew Rd, Suthep, \\ Mueang District, Chiang Mai, Thailand 50200. E-mail: Nawatrot_kaw@hotmail.com
}

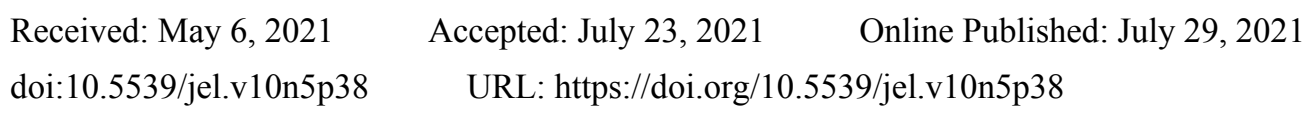

\begin{abstract}
This article aims to: (1) study the context of the local wisdom Mohom for self-reliance of Ban Thung Hong community, Phrae; and (2) to study the local wisdom management of Mohom for sustainable inheritance and lifelong learning, by implementing qualitative research methodology. Data collection was conducted by an in-depth interview on the community leader, the community philosopher, and Hom laborers, participatory and non-participatory observation, and collection of related secondary data. The results of the content analysis revealed that 1) The context of the local wisdom Mohom is related to participatory Hom management for self-reliance of the community in Phrae, via accumulation, transfer, and inheritance of knowledge from generation to generation. This is called "Hom Culture" which consists of self-reliance in three factors: (1) Hom Culture: community economy for self-reliance; (2) Hom Culture: social and cultural system for self-reliance; and (3) Hom Culture: natural resource and environmental management for self-reliance. Hom is therefore a culture that connects the community, and is significant for the community in Phrae to conserve the identity and value of the local wisdom, a foundation for self-reliance of the local community; and 2) Study on the local wisdom management of Mohom for sustainable inheritance and lifelong learning revealed that there are seven knowledge management processes in Ban Thung Hong community: 1) knowledge identification; 2) knowledge creation and acquisition; 3) knowledge organization; 4) knowledge codification and refinement; 5) knowledge access; 6) knowledge sharing; and 7) learning. Additionally, there also exists Hom cultural management in the community through the Mohom Dyeing Learning Center, in which community members design the communication process of Hom culture for participatory self-reliance in the community, and response to demands of the community via "Lifelong Learning" applied in the context of the community regarding learning among the members, or between members and teenagers, which eventually lead to the development of learning places, travel destinations, and local database as the learning sources of the community. Additionally, this allows those interested in the community, particularly the local young population, to study the community, which encourages "Strong Citizens of Phrae" via knowledge management, authority distribution, and educational opportunity creation, with the purposes to encourage equality and bonds in the community, alongside an appreciation of resources in one's own community. One of the important expectations of the community is to preserve the lifestyle pattern of Hom culture, despite the social changes from external sources which influence the role of the community.
\end{abstract}

Keywords: hom culture, local wisdom management

\section{Introduction}

Local wisdom is an essential cultural asset of a local community, which are accumulated through knowledge, experience, and intelligence of the members of the community for self-reliance, by converting existing resources and knowledge into a new value which corresponds with the context of the community. Local wisdom is considered the knowledge, concept, and abilities of the population obtained via adaptation and survival in an external social and cultural environment and are applied to solve the issues within one's local community. Therefore, local wisdom is not only specialized knowledge, but also "Integral" knowledge, which combines knowledge from various specialization, and creates or reveal the lifestyle of the community culture. In other words, local wisdom reflects concept, belief, context of resources, and community traits, as observed by social rules, relationship with family or local community members, and traditions which are the foundation of the 
members. This is because local wisdom is what the members utilize to solve the problems and has been proved to be compatible with another lifestyle of the community (Chuan, 2004).

Phrae is famous for its local wisdom "Mohom Ban Thung Hong" according to the community philosopher. Historical documents revealed that Ban Thung Hong's villagers were refugees from Phuan, Laos, in 1817. Their main occupation was Mohom clothing, unique local wisdom of Phrae which has been inherited from generations. In this research, I would like to call it "Hom Culture", since Mohom Ban Thung Hong relates to the.

"Hom" is an annual plant with a straight trunk, branches, oval-shaped zigzagged leaves, and flowers blooming in bunch. Many flowers hang between the gaps of the leaves. Their purple petals are connected in form of a slightly bent straw. The tree is 50-100 centimeter high and grows well in places with dim sunlight. It has high humid, and always produces drips. Hom leaves can be used in production of blue dye when fermented for two years, and can be stored indefinitely, depending on the growth speed. In case of Large Hom trees, both branches and leaves are used, while in case of small trees, leaves are mainly used. The branches and leaves are fermented in the pot according to the process inherited from generations. Additionally, parts of Hom trees are used in local medicines, such as leaves whose medicines can cure fever, headache due to the cold, sore throat, bronchitis, tonsillitis, and ophthalmia (Kamonpon et al., 2009). Therefore, Hom is considered a plant of the world. Despite blue dye being widespread globally for thousands of years and its similar usage, it is assumed that at Phrae, Mohom clothing was transferred from the refugees to Phrae due to the war, and that the population was forced to become the labors, since there was little population in Phrae, hence the need of labors for the production. This caused "Mohom garment" to become the symbol of Phrae. Natural dyeing process of Mohom indicates that there exist a variety of natural resources in the region. The process also resolves the issues of chemical usage in general dyeing process, which affects the soil, underground water, and the air.

However, it is revealed that local population (Lan $\mathrm{Na}$ ) in the northern region and various provinces in Thailand tend to wear Mohom garment made in Phrae due to its reputation. The garment is renowned for its quality, such as the durability, Hom dyeing color, simplicity, and comfortable texture. The majority of Mohom garment production are performed in form of household industry, of which the local wisdom had been inherited from the predecessors. Mohom garment can be considered as an ancient local product, and one of the identities of Phrae which generates reputation and economic value for the province, whilst maintaining the local wisdom. Currently there exists several Mohom garment producer groups in Phrae, such as Thung Hong, Muang Mor, and Kanchana of Mueang Phrae; Wieng Thong and Don Moon of Soong Men. The largest and most famous production site is in Thung Hong of Mueang Phrae.

Social and environmental changes generally cause competition and struggle for survival of the community and its members, which encounter problems such as production, resources, and marketing and network. Nowadays, it is revealed that Hom natural dyeing garment is on the verge of disappearance due to rapid development of technology, such as chemical dyeing, and industrial dyeing, which has rapidly become widespread in Thung Hong, Phrae, the market of Mohom garment. The traits of Mohom garment of Phrae are intrinsic to its local wisdom and natural conservation since it primarily uses natural dyeing color. Hom is a plant used as a dyeing material. Currently, the plant is on the verge of extinction due to harvest from natural sources, and low rate of cultivation, causing the remaining resources to be insufficient for the demands of Mohom garment producers. This forces them to import Hom from Sakon Nakhon and Laos, of which the plants are also on the verge of insufficiency (Monthira et al., 2015).

As a local person, I have intention to support Mohom products, since Hom tree is a cultural plant of which importance has been disregarded. People recognize Mohom garment as the uniform of Lan Na, but do not know the origin of Hom or Hom culture. It is not also mentioned in social study textbooks, that Hom tree is a global and local plant essential for Phrae and is used in garment production which generates high revenue for Thailand. Nor the curriculum is integrated into local classrooms.

Therefore, conservation of local wisdom, recovery of self-sufficiency economy, and Mohom curriculum to conserve the culture should be prioritized so that people understand the importance and value of Hom, particularly local population, teachers, and students.

Consequently, this research on local wisdom management Mohom for sustainable inheritance and lifelong learning will apply the learning management process to Hom dynamic local wisdom management for lifelong learning, which is considered the knowledge from experience, concepts, and beliefs that are connected to local lifestyle culture, in addition of being the knowledge which is rooted and inherited from generation to generation. Therefore, I give precedence to the application of knowledge management to acquire the knowledge inheritable to those who are interested in Hom local wisdom. The purpose of this is to encourage "Strong Citizens of Phrae", 
who are aware of the importance of the local wisdom and issues on environment, inheritance, existence, survival, and development of Hom culture in the future.

\section{Objectives}

1) To study the context of the local wisdom Mohom for self-reliance of Ban Thung Hong community, Phrae.

2) To study the local wisdom management of Mohom for sustainable inheritance and lifelong learning.

\section{Theoretical Backgrounds and Theoretical Framework}

\subsection{Concepts of Knowledge Management for Self-Reliance}

Knowledge management is the development and discovery of potential knowledge to enhance performance. It focuses on collaborative learning by the process and tools of integration for the benefit of the organization, group, network, and society. In a learning society, members are assigned their essential role, which is collaboration-oriented knowledge management.

Therefore, the knowledge management process is a basic process of operation and self-reliance. In this research, I have summarized the concepts of the learning management process, which consist of seven steps as follows (Office of the Public Sector Development Commission, and Thailand Productivity Institute, 2005):

1) Knowledge Identification: identification of knowledge of the community, its forms, ownership, and types of existing and insufficient knowledge.

2) Knowledge Creation and Acquisition: acquisition of knowledge from various sources, or creation of new knowledge from an existing one.

3) Knowledge Organization: enables knowledge users to search and apply the knowledge to their benefit.

4) Knowledge Codification and Refinement: codify the knowledge in an easily comprehensible and applicable form, or standardization of such form.

5) Knowledge Access: acquired knowledge does not possess value if it is not publishable, therefore storage and publication methods are necessary.

6) Knowledge Sharing: storage and sharing of knowledge, which may be achieved only on external knowledge. In the case of internal knowledge, communication for knowledge exchange is required.

7) Learning: refers to the learning of the personnel, and application of the knowledge for problem solutions and development. Without development, knowledge may become useless.

\subsubsection{Objectives of Knowledge Management for Self-Reliance}

The objectives of learning management for self-reliance consist of three factors as follows (Community Development Department, 2016):

1) Quality of life development: knowledge management allows the application of acquired experiences to the development of one's occupation.

2) Human development: created knowledge can be inherited by general individuals regardless of their familiarity with the knowledge. This supports the individuals with development, well-round knowledge, and self-reliance.

3) Community development: as mentioned earlier, communities, in general, possess their knowledge, therefore knowledge management helps organize such knowledge, resulting in the knowledge which is easily comprehensible, applicable in problem solution, or creation. This means that a community with knowledge management can constantly develop itself without a repetitive strategy.

Therefore, it can be concluded that knowledge management for self-reliance combines knowledge in a community, which may exist in each of its members or document, and organize into a system, so that community members can access such knowledge and develop themselves effectively.

\subsection{Concepts of Local Wisdom Inheritance and Lifelong Learning}

Local wisdom inheritance is considered a process of learning and development for a human to preserve the identity of their ideas, beliefs, methods, and guidelines, by relying on the cultural inheritance process, which circulates infinitely. In this case, local wisdom inheritance refers to the inheritance of that which consists of concept, form, content, and method.

Local wisdom inheritance can be considered in three dimensions: 1) Human dimension, which refers to inheritance from an individual to another individual; 2) Space dimension, which refers to inheritance from a place to another place; and 3) Time dimension, which refers to inheritance from a period to another period. It is 
revealed that a successful local wisdom inheritance process requires the probability of inheritance, and consistency with the era. It is not an only inheritance from generation to generation, but also processes of learning, change, adaptation, re-interpretation, re-creation, transmission, and inheritance. This is because the survival of local wisdom requires adaptation to the era. Therefore, culture or local wisdom is dynamic and resilient (Chanawee et al., 2017).

\subsubsection{Importance of Local Wisdom Inheritance and Lifelong Learning}

Community culture or local wisdom determines the lifestyle of members of society. They also indicate the development or regression of the society which affect the development of the nation, since it depends on the development of its population. According to previous Thai National Economic and Social Development Strategies, national development requires equilibrium of human development, of which the details are as follows:

1) Quality society: development of members in the society in terms of knowledge and a good way of life skills by adhering to self-sufficiency and self-reliance is necessary.

2) Wisdom and the learning society: provide the members with access to lifelong learning, thinking, and problem-solving skills. Additionally, encourages the members to collaboratively develop and inherit their culture, alongside conservation of local traditions.

3) Generosity society: enhances the members with morals, ethics, and good values, in addition to codependency, unity, and pride in their local community.

Therefore, local wisdom inheritance is necessary for human and social development, which provides results as follows:

1) Visualization of the lifestyle of the local community, and religious, social, and cultural creativity.

2) Cooperation of the community on the inheritance of good traditions, application of local wisdom to benefit its members, sustainable development, and global reputation.

3) Permanence of local wisdom.

4) Lifelong learning, and encouragement of strong citizens who are aware of the importance of local wisdom.

\subsubsection{Guidelines of Local Wisdom Inheritance and Lifelong Learning}

The permanence of local wisdom requires cooperation from all related sectors, which can be achieved with the following methods:

1) Data collection on local culture and wisdom collects the data through both local members and documents to study the essence, identity, and benefits of the local culture and the wisdom. This contributes to acknowledgment in the younger population and application in contemporary lifestyle.

2) Promotion of the value of the culture and local wisdom through education, both systemic and non-systemic, especially those which raise awareness of the community identity. This contributes to confidence and adaptation to changes caused by external culture.

3) Cultivation of responsibility on conservation and inheritance of the culture and local wisdom, to raise awareness on their importance. Additionally, private sectors and educational institutes must cooperate on promotion, support, and collaboration of knowledge and academic management.

4) Cultivation of attitude that all members in the society must create, recover, and preserve natural and cultural environments so that they acknowledge the effects of these environments in their daily life.

5) Establishment of a public relation center of cultural and local wisdom works, by implementing an information network that is easily and immediately accessible, and adaptable to the lifestyle.

Therefore, I have concluded that concepts of inheritance of local wisdom and lifelong learning are correspondent to each other, which contribute to the conservation of the cultural and local wisdom heritages. They are also those which future generations should acknowledge or be aware of, since those heritages indicate the identity of the community and society and contribute to attachment or love for their own community, self-reliance, and sustainable development. The main idea of these concepts is the accumulation and inheritance of cultural and local wisdom heritages through various processes and social innovations in the context of the local community.

According to the review of knowledge management for self-reliance, and concepts of local wisdom inheritance and lifelong learning, I have synthesized the connection of this research (Figure 1). 


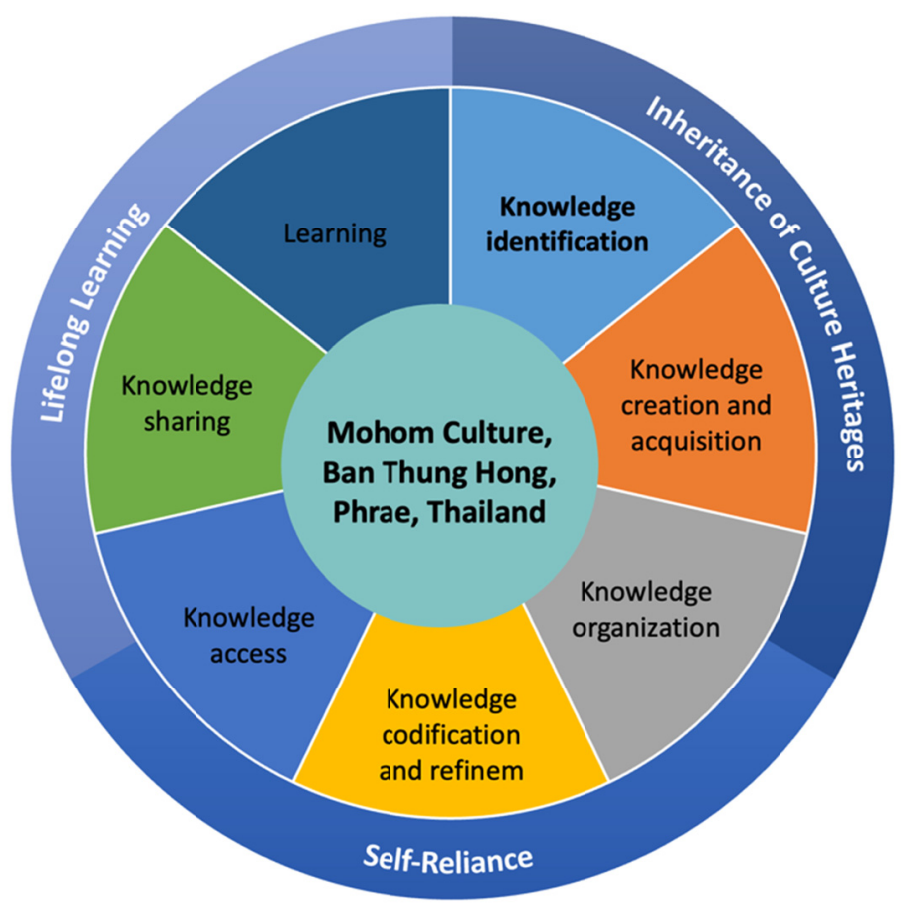

Figure 1. Research concepts

\section{Related Literature Review}

1) Ali Intezari (2017) studied "Looking beyond knowledge sharing: an integrative approach to knowledge management culture" and found that the main process of knowledge refers to knowledge sharing, knowledge creation, knowledge management, and knowledge application. The successful strategy of knowledge management relies on correct understanding and management of infrastructure, and an effective process of core knowledge. He states that technology infrastructure is an important factor of knowledge management including integration of knowledge and decision-making and practice on such management with the support of communities or corporate cultures on the main process of knowledge for sustainability and lifelong learning.

2) Suthisa Songleknok et al. (2015) studied "Knowledge management process of indigo-dyed cloth community business" according to the value chain and facilitating factors of knowledge management and dyed cloth community business. Most knowledge is tacit knowledge consisting of 6 steps in knowledge management: 1) knowledge identification, 2) knowledge acquisition, 3) knowledge creation, 4) knowledge organization and storage, 5) knowledge sharing and transfer, and 6) knowledge utilization. They found that the factors facilitating the success of the learning management process and community business of indigo-dyed cloth through a value chain were 1) leader, 2) income, and 3) trust.

3) Boonsong Auaearoon (2005) studied "Construction of learning units on mohom Sungmen local wisdom, Sungmenchanupatham School, Phrae Education Service Area 2". The purposes of his research were to 1 construct and assess the learning units of mohom Sungmen local wisdom used in teaching the subject area of citizenship, culture, and lifestyles in social studies at the 4th interval. The study results showed that 1) the learning units and the teacher's manual for the lessons of social studies, relations, and cultures in the 4th interval at Sungmenchanupatham School, Phrae Education Service Area 2 consisted of 4 lesson plans with 3 periods per lesson: Lesson 1-the history of mohom cloth, Lesson 2-materials for making mohom clothes, Lesson 3-the process of making mohom clothes, and Lesson 4 - the products and markets of mohom clothes. Regarding the assessment, the learning units and the teacher's manual on mohom Sungmen local wisdom were found at the high-quality level.

4) Charin Mangkhang et al. (2015) cited in Grit Piriyatachagul (2020) studied "Curriculum development on Miang at Thep Sadej Sub-district, Doi Saket District, Chiang Mai Province. They found that local wisdom with community resources management for local curriculum management consisted of 4 learning units: Unit 1 - community history in different paths, Unit 2-arts and cultures of harvesting Miang dancing, Unit 3 - community power in Miang forest preservation, and Unit 4 - citizenship and environmental management in 
Miang lifestyle. This local curriculum helps raise the students' awareness of the importance of community cultures, values, and identity of Miang community way. This curriculum is valuable in the empowerment of learning in roots recovery, in the meaning of sustainable community way of life, and in knowledge application for empowering lifelong learning and strengthening youths of the community.

\section{Method}

\subsection{Research Design}

This study was qualitative research to investigate the body of knowledge which is the local wisdom of the community. This study implementation needed meticulousness, carefulness, in-depth, and continuity of the study period to obtain facts that could reflect different perspectives in the contexts of mohom local wisdom for self-reliance of Ban Thung Hong Community in Prae Province. The data were used for analyzing knowledge management in mohom local wisdom for sustainable succession and lifelong learning. The study results were from the descriptive analysis.

\subsection{Area of Study}

The area scope of this research was at Ban Thung Hong Community in Prae Province. This community has a community structure with knowledge management in mohom local wisdom for sustainable succession and lifelong learning in terms of 1) economy, 2) societies and cultures, and 3) natural resources and environment.

\subsection{Scope of Contents}

The scope of contents for this research consists of 1) context of Hom Baan Thung Hong, Phrae, Thailand, with the research topic of Hom culture and its relationship with the community and self-reliance; and 2) knowledge management process of Mohom local wisdom, Phrae, with the research topic of the methodology of knowledge management for Mohom local wisdom, Phrae, for sustainable inheritance and lifelong learning.

\subsection{Population and Sample Group}

In this research, the population is categorized into two main groups: 1) five or more community leaders and philosophers, chosen by purposive sampling; and 2) five or more Hom local entrepreneurs, chosen by accidental sampling. Additionally, the population consists of an unspecific number of community members who can provide information during the field study.

\subsection{Research Tools}

1) In the study, an in-depth structured interview was used. The researcher prepared the question structure in advance before interviewing the sample group to obtain the data about the contexts of mohom local wisdom for self-reliance of Ban Thung Hong Community in Prae Province and about knowledge management of mohom local wisdom for sustainable succession and lifelong learning.

The interview was tested on validity and reliability by experienced experts in social studies and area-based studies to obtain valid and reliable data for systematic analysis and inference.

Regarding the interview quality testing, the index of item objective congruence (IOC) was analyzed on contents validation by 3 experts in examining the question items and giving comments on each item. The IOC was found at 0.78 .

2) The field study record was used in the participant and non-participant observations to records various details during fieldwork for data collection. The collected data were used in combination for data analysis and explanation of the phenomenon.

\subsection{Method of Collecting Data}

1) Documentary research: data is collected through documents, books, academic journals which contain related concepts, theories, and research. The data collected by this method prioritize that which is not obtained by interview.

2) Field study: through participatory and non-participatory observation, including an interview of community leaders, community philosophers, and the community members who are Hom laborers.

The test of completeness, validity, and reliability of the data is conducted by 1) triangulation technique; 2) verification of data with the providers

\subsection{Data Analysis}

The study results are presented according to the study purposes, by implementing the content analysis method of Hubbard and Power (1999), which determines four steps of qualitative data analysis process as follows: 1) 
preparation of data acquired through documental research, interview, group conversation, and questionnaires; 2) review of research questions; 3) organization of data by its relationship; and 4) data analysis by determining primary and secondary topics, followed by summarization by data groups, and presentation of study results in form of descriptive analysis.

\subsection{Trustworthiness and Quality in Studies}

In this study, Basic criteria were used to determine the value of Trustworthiness with the Lincoln and Guba's Trustworthiness Guidelines (1985): 1) Credibility, 2) Dependability, 3) Confirmability, and 4) Transferability. Furthermore, the data is presented to informants and related people to review all stages of the study by inquiring back to a group of informants on various issues as member checking and familiarize the informants to enable them to behave as phenomenological validity.

\subsection{Ethical Considerations}

To observe the highly confidential nature of the study, no particular names were mentioned in the study. The identity of the respondents was undisclosed. No personal opinions were given by the researchers, only information and results based on the data to be gathered. The research participants should not be subjected to harm in any way to the results or findings of the study. The study considered high respect for the dignity of research to be prioritized and full consent should be obtained from the participant before the study.

\section{Results}

The results are classified follows specific objectives and presented in 2 dimensions as follows:

\subsection{Context of Mohom Local Wisdom for Self-Reliance of Ban Thung Hong Community in Phrae}

In the study on this dimension, two research tools are used: 1) field study record, through the participatory and non-participatory interview, with the purposes to record the details during the field study; and 2) structured interview, through an interview on community leaders, community philosophers, and the community members who are Hom labors. The results of data analysis are categorized into three dimensions for easy comprehension, consisting of 1) Hom culture: local economy for self-reliance; 2) Hom culture: a social and cultural system for self-reliance; and 3) Hom culture: natural and environmental resource management for sustainable self-reliance. Study results revealed the following:

1) Hom culture: local economy for self-reliance. Study results revealed that the main occupation of Ban Thung Hong population is Mohom garment production, which is local wisdom inherited from many previous generations, and the identity of Phrae that contributes to the selection as an OTOP Village Champion Handicrafts Tourism. Hom culture is considered a participatory economic self-reliance system of Ban Thung Hong community members since Mohom garment production relies on the participation of the members which consists of 1) Hom farmers; and 2) Hom manufacturers. Study results revealed that the primary Hom cultivation fields of Phrae are in Na Tong, Nam Jom, Nam Kay, Na Khu Ha, Mae Lua, and Huay Ma, Mueang Phrae, Phrae, with an approximate area of 100 rai. Parts of the plant used in dyeing are leaves and fresh treetops. Hom is sold for 5-7 baht per kilogram. Local people tend to ferment the plant into wet Hom. Fermentation of 10-12 fresh Hom will result in approximately 2.5 kilograms of wet Hom, which can then be sold for 80-100 baht per kilogram. Currently, there are various issues regarding Hom cultivation, such as restriction on cultivation fields due to humid weather, insufficient materials for production, or replacement of natural dyeing by chemical dyeing.

Hom manufacturing site is in Thung Hong, Phrae, which is the largest Hom dyed garment production site in Thailand. Local people produce navy color from wet Hom, and the color is used in dyeing garments. The garment-dyed this way is called "Mohom garment", a durable and light cotton garment that is comfortable, provides balanced temperature, and is resistant to stains. The garment is simple and is suitable for various generations and opportunities. At present, Mohom garment has been developed into various styles, and the community enterprise of Mohom Thung Charern natural dyeing called "Union of Mohom Producers of Thung Hong, Phrae, Limited" was established by the assembly of Mohom entrepreneurs in the community, since there exist productive assets, wisdom, and skills. Additionally, according to the in-depth interview of Mohom entrepreneurs in the community, Hom natural materials have replaced chemical materials in the production, which later becomes an appealing aspect that generates income for the entrepreneurs at approximately 40,000 baht per week or as much as 100,000 baht per month per household.

From the interview with the chairman of the community enterprise about network building for mohom production and hom plantation, "Most entrepreneurs bought raw hom to dye it at home. They do not grow it, but they buy it from Ban Na Khu Ha and Ban Na Tong at 300 baht a kilo" (From the interview on 9th August 2017). According to the interview with the hom entrepreneur, "In the community, the members of the mohom community 
enterprise do not seriously join together although the enterprise has an organizational status. The activities to support and promote mohom products are not concrete and they lack cooperation, meeting, knowledge sharing for clearly setting plans, policies, strategies, and measures to co-operate in developing mohom products to be unique" (From the interview on 9th August 2017).

2) Hom culture: social system and self-reliance. According to the study, hom culture had a relationship to the community traditions, beliefs, societies, and cultures. The study results have described the history of hom culture with Chao Chompoo, important traditions, and local dressing of Phuen villagers in Ban Thung Hong, etc. as follows:

(1) Ancestors of the community. According to the interview with the community leader and the synthesis from related papers and research, Chao Chompoo was the 43rd ruler of Phuen City with accession to the throne in 1782, and he had reigned the city for 19 years before he died in 1801 in Vientiane. Historically, it was told that Chao Chompoo was a very clever ruler who could solve emerging problems with brave and carefulness. In his ruling dimension, he cultivated people to be diligent, patient, and harmonious as well as to make honest careers. In terms of religion, he built temples, fostered monks to further study dharma, and set out Heat-Kong (a custom-guidelines for ruling the city or conventional practice in the community) as a model practice for people.

Once, the Siam King gave a royal command for Chao Chompoo and Phra Chao Vientiane to raise an army to attack Luang Phrabang and they could defeat it successfully. After that, Chao Chompoo was not subordinate to Luang Phrabang and Vientiane anymore as he announced independence. Therefore, Chao Non of Vientiane City raised an army to attack Phuen City and killed Chao Chompoo. In the killing ritual, the lightning hit the killing spear used to kill Chao Chompoo, so Vientiane soldiers were frightened and ran away. When Chao Non knew about the amazing incident, he thought that Chao Chompoo was a person with power of merit, so he allowed Chao Chompoo to rule Phuen City. According to this incident, Phuen villagers have given importance and full respect to the sky, so Kham-fah (holding the sky) Tradition occurred and has been practiced since then. On the Kham-fah day, every villager stops work to make merits and have fun together. It is believed that if anyone is not obedient and goes out to work, that person may be hit by lightning. Kham-fah Tradition is important to Tai Phuen villagers at Thung Hong Sub-district, Muang Prae District, Phrae Province. This tradition is annually held with the belief that a person who does not participate in this ritual, he/she will be hit by lightning. Villagers in the nearby villages who believe in this tradition will also join the ritual.

(2) Tradition and beliefs. Hom culture has a connection with Kam Fa culture. According to the in-depth interview on community leaders and philosophers, it is revealed that the culture indeed has a connection with Mohom of Thung Hong population due to obvious expression, as observed from male and female uniforms of Mohom according to the old tradition. Kam Fa is an old tradition that has been adhered to until the present, an important identity, and a tradition that indicates respect to predecessors and angels in the sky, who bless the rains for agriculture. On Kam Fa Day, Thai Phuan Ban Thung Hong people will wear traditional Mohom garments to raise awareness of Mohom cultural value for younger generations. Additionally, it is revealed that Mohom color is related to beliefs, which indicates the unity and diligence of Thai Phuan.

(3) Societies and community cultures. It was found that hom culture related to the dressing of Tai Phuen villagers at Ban Thung Home in Phrae Province. Mohom is a unique dressing of Thung Hong villagers and people in Phrae Province. Local dressing made of mohom is regarded as the local dressing of Thung Hong villagers. Men usually wear "Seua Kui Heng" which are round-neck shirts with short sleeves, front slits tying with buttons or strings; and Thai fisherman pants called "Tiew Ki" with loincloths instead of belts. Women usually wear v-neck or round-neck blouses with long cylindrical sleeves and front buttoned slits and long sarongs called "Sin Lae" with a dark background, two red stripes at the edge of sarongs, and red waistbands.

According to the interview with the community leader, "Ban Hong ancestors had knowledge how to make mohom shirts/blouses. Previously, they made mohom dresses for going to work. People who did not have time to make and dye hom bought it. Therefore, there have been mohom dresses sellers but the shops at that time were not as big as the mohom shops at present. When the demand of community people increases, there are many mohom makers and this has developed into the shop of Thung Hong dyed fabric." Moreover, in the in-depth interview, the community sage said that dressing in the past does not have many patterns and colors. Each household weaved cotton or calicos and made dresses for use in the household. Most dressings were in cotton white until they found that hom plants in the community could be used to dye fabrics into dark blue, so they dyed the fabric into hom fabric. One mohom shirt can be used throughout the year until it is worn out. After use, if mohom clothes are pale, they can be re-dyed (From the interview on 9th August, 2017).

Furthermore, the abbot of Thung Hong Tai Temple told that "Our temple attempt to take the role to support Ban 
Thung Hong Community by allowing people to use the sermon hall area for meeting and discussing mohom-making activities. I give them opinions about the preservation of traditional hom culture to prevent it to disappear from our Ban Thung Hong Community. According to the legend, Ban Thung Hong mohom-making relates to Tai Phuen ancestors who immigrated from the Lao People's Democratic Republic, so our village is famous for the Kham-fah Tai Phuen event. Therefore, we should preserve and cherish our traditional hom culture to be together with Ban Thung Hong. The temple also supports the tradition of Kham-fah Tai Phuen Ban Thung Hong by arranging the parade events" (From the interview on 9th August 2017).

3) Hom culture: natural and environmental resource management for sustainable self-reliance. Study results revealed that Hom is a biome plant that indicates the richness and pureness of the forest since it resides under the shade of large trees. The plant grows in the humid and upstream forest. Due to the nature of the forest, both small and large plants are codependent. Hom tree obtains fertilizer and minerals from large trees, and in turn, large trees rely on small trees to preserve humidity. Local people cultivate Hom trees in their area, by planting between other plants in the garden, or by planting on the edges of the rice field for maximum utility of the area. Cultivation of Hom trees under the shade of large trees contributes to its beauty and long-term production since tree shades support the reduction of sunlight concentration, and preservation of humidity from fallen leaves which degrade into fertilizer for both Hom and large trees, in addition to prevention of soil collapse. Additionally, the cultivation of Hom under tree shades reduces deforestation issues, which contributes to the coexistence of agriculture and sustainable forest conservation. Planting Hom among other trees in the forest contributes to the biological diversity of both plants and animals and mutual assistance in the ecosystem. According to the interview on Hom farmers, regarding Hom natural resource management, local people insist that they must be able to live with and benefit from the forest. Therefore, Hom occupation is what contributes to sustainable preservation of the forest.

\subsection{Knowledge Management of Local Wisdom Mohom Ban Thung Hong, Phrae, for Sustainable Inheritance and Lifelong Learning.}

In the study about knowledge management on mohom local wisdom at Ban Thung Hong in Prae Province for sustainable succession and lifelong learning, the researcher used the in-depth structured interview with the community leader and the community sage. The study results revealed that the community had the knowledge management process through 7 components of knowledge management according to the concept of the Office of the Public Sector Development Commission and Thailand Productivity Institute. The 7 components of knowledge management were 1) knowledge identification, 2) knowledge creation and acquisition, 3) knowledge organization, 4) knowledge codification and refinement, 5) knowledge access, 6) knowledge sharing, and 7) learning. The study results can be summarized as follows:

1) Knowledge identification: study and comprehension the circumstance and Hom cultural context of the community, to identify the Hom entrepreneurs, and expert skills of the members. The process begins from procurement of materials and tools, cultivation of Hom tree, production of wet Hom, the craft of Hom pot, Hom breeding, and Hom dyeing, etc. Local people determine the local wisdom knowledge regarding the usage of materials and natural resources in the community to create new products, which generate income for the households and the community. Additionally, the community demand is determined to inherit local wisdom by focusing on the participation of community members.

2) Knowledge creation and acquisition: the community may (1) acquire the knowledge from the groups and their members, or is appointed to acquire such knowledge, by methods such as interview on local people or Mohom network, operational training, or study visit; (2) transfer the knowledge determined by affiliated organizations; (3) publish the knowledge via media, such as books or magazines which provide knowledge on product design and development; (4) sell its products through the establishment of the shop, which provides experience and knowledge, such as product design of various occupations, or knowledge from other organizations and customers, which are useful for product design and development.

3) Knowledge organization: the community implements simple organization and storage systems for the knowledge of the product through sample products. While knowledge regarding job skills is store inside an individual via recurring action, which contributes to knowledge, skills, and proficiency.

4) Knowledge codification and refinement: the community lacks clarity because most knowledge belongs to tacit knowledge, which is processed and stored inside an individual. Therefore, knowledge management in terms of processing is merely simple processing, which lacks its own clear system.

5) Knowledge access: the community has determined the patterns and methods which provide access to the knowledge of Hom culture and was provided with support from Thung Hong Municipality through public 
relation or operational training. So far there have been several students, teachers, researchers, and public and private sectors who study the traditional production of Mohom garment, which is available for trial.

6) Knowledge sharing: this refers to exchange of knowledge among group members, or external individuals through telling, exhibition, and experiment, using the following methods: (1) transfer of knowledge to family members and community enterprises during the recovery of knowledge of Mohom culture; (2) transfer of knowledge to those interested in Hom via telling or demonstration, in which the knowledge consists of both simple and expert one, especially perseverance an recovery of Hom pot in an event that the pot is on the verge of death; and (3) transfer of knowledge via local educational institutes, and publication on the website.

7) Learning: Ban Thung Hong community implements the strategy of collaborative knowledge management for sustainable inheritance and lifelong learning, by determining three strategies: (1) development of producers, entrepreneurs, and marketing, by increasing the performance of producers, and promotion of marketing channels; (2) development of community products by knowledge; and (3) development of lifelong learning process and sustainable inheritance of local wisdom, which includes identification, acquisition, inheritance, and publication of local wisdom.

The knowledge management process on mohom local wisdom at Ban Thung Hong, Muang District, Phrae Province is the management on "community cultural capital" with the purposes for 1) existence, 2) adaptation, 3) survival, and 4) lifelong learning on hom culture. Hom culture is regarded as knowledge from experience, ideas, and beliefs with cultural ways of life in the community, and it is regarded as tacit knowledge of individual people who transfer such knowledge from generation to generation. The knowledge management model which the researcher found can be used as guidelines to gain knowledge which can be transferred to people who are interested and intentional to learn about the local wisdom of hom culture to reinforce "Strong Citizens of Phrae" with awareness of the importance of local wisdom, emerging environmental problems, succession, existence, adaptation, and development of hom culture with sustainability.

According to the interview with the president of Mohom dyeing learning center, the organization was established based on the concept of "the one who knows you best, is yourself". Therefore, the community transfers knowledge via data storage, which consists of six dimensions as follows:

1) Community history: the data is collected through documents, interviews, and learning centers in the community. Afterward, it is organized starting from the refuge of Phuan people from Chiang Khwang to their establishment of residences in Thung Hong. The data also includes the structure of the government system, infrastructures, language, tradition, arts, cultures, rituals, beliefs on ghosts, foods, clothes, and important events of each era.

2) History of important figures: the data collected through the selection of community members who possess experience, knowledge, abilities, and reputation. This process contributes to knowledge exchange among the members. Conversation causes them to form good human relations among themselves and raises interest in important figures of their community, which causes admiration, encouragement, and value in those figures.

3) Community map: starting from data collection through the application of Thung Hong Municipality to the prototype for area observation, followed by scheming field study which includes field data collection and identification of coordination of each place in the community. Afterward, data collected through field study is applied in symbol designation and description. Creating a community map contributes to the revelation of information on the physical location of the places and the relationship of community members. Knowledge exchange among the members helps raise their awareness of the importance of their community.

4) Community calendar: data collection is conducted through interviews with community members and philosophers, and field study. The collected data utilized in the community calendar is categorized into (1) economic and occupation data; (2) important local traditions and cultures; and (3) beliefs and rituals. Creating a community calendar helps review the situation of the local economy, occupation, rituals, beliefs, traditions, and cultures. Additionally, it contributes to the enhancement of pride in one's community, and annual activity schemes corresponding to the life of community members. It can also be sustainably developed into traditional travels in the future.

5) Relative's chart: this is created by researching existing documents in local temples, followed by validation of the expansion of the head family, whether its members are dead or alive. Afterward, the interview of the head families of each living lineage, to record the data of branch families and update the existing database. By doing so, an organized and accurate database is achieved and ready to use in searching relatives in the future.

6) Mohom entrepreneurs: Mohom an important occupation that generates significant income for Thung Hong 
people, since the community is the essential site of Mohom production, clothing, design, shops, and learning center in Phrae. It is also a popular traveling destination for all ages. Additionally, study results revealed that the younger population tend to return to inherit Mohom business, and apply and design garments and products to correspond with the modern age, whilst preserving the traditional lifestyle and local wisdom, and promoting friendliness to the environment

Therefore, knowledge management of Ban Thung Hon community in Phrae, of which the whole community holds the ownership, preserves, and benefits from Hom resources. The community members also collaborate in the design of Hom inheritance process for self-reliance, through the participation in the community, to respond to demands which have not been realized or developed through systemic education. Rather, it is the non-systemic education, or "Lifelong Learning", which is applied to the context of mutual learning among local people, or between local people and younger people. This "lifelong learning" contributes to development of learning sources and cultural travel destinations of the community, development of local database system as a resource for local learning, and development of learning area which provides access to learning of local style and culture. One of the important expectations of the community is to preserve the lifestyle pattern of Hom culture, despite the social changes from external sources which influences the role of the community, since community members expect to preserve their story of Hom culture, which is a part of local cultural assets, by reflecting the local way of life through the tales for children, teenagers, or those interested. Design of the community for development of travel destination and learning center is therefore the true need of the local people, who transfer their knowledge and experience for future generations in their community, and travelers.

Therefore, knowledge management of local wisdom Mohom, Ban Thung Hong, Phrae, for sustainable inheritance and lifelong learning means the recovery and application of Hom organic empowerment through the design of knowledge management which corresponds to the real-life, under the economic and social context of the community. Such a process is achieved by enhancing citizens with the quality through authority distribution and provision of educational opportunities, to support equality for teenagers and the community. This process also raises awareness of local resources by promoting teenagers to learn with local people through the situation of local resource management, in form of management and inheritance of local wisdom which is an asset of strong citizens, and a cultural asset. This contributes to collaborative learning, development of products, lifelong learning, and ultimately management of local thinking systems based on the community, which can sustainably create values and prices.

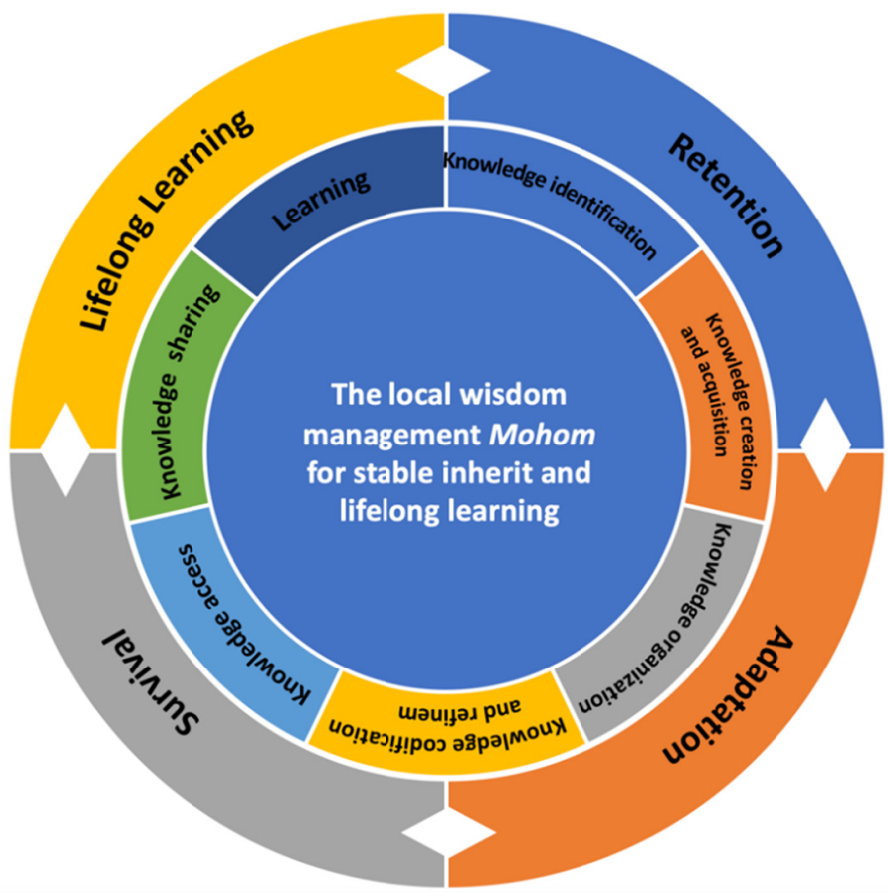

Figure 2. The local wisdom management Mohom for stable inherit and lifelong learning 


\section{Conclusion and Discussion}

1) Context of local wisdom Mohom for self-reliance of Ban Thung Hong community in Phrae: The context of the local wisdom Mohom is related to participatory Hom management for self-reliance of the community in Phrae, via accumulation, transfer, and inheritance of knowledge from generation to generation. This is called "Hom Culture" which consists of self-reliance in three factors: (1) Hom Culture: community economy for self-reliance, which consists of the participation of Hom farmers and Hom manufacturers; (2) Hom Culture: social and cultural system for self-reliance, which relates to Kam Fa tradition and the uniform of Thai Phuan people of Ban Thung Hong, Phrae; and (3) Hom Culture: natural resource and environmental management for self-reliance. Hom is a biome plant that indicates the richness and pureness of the forest, which requires mutual assistance. Additionally, the cultivation of Hom trees contributes to the reduction of deforestation, which in turn contributes to the coexistence of sustainable agriculture and forest conservation. This corresponds to Grit Piriyatachagul et al. (2020) who stated that local resources management is generally connected to the local lifestyle, in terms of economy, society, culture, and natural and environmental resources. These factors are integrated into the mutual lifestyle of the community which has been inherited from many previous generations. It also corresponds to Thongchai Phuwanaphawichit (2015), who stated that local resource management is a process that correlates with the society, culture, local wisdom, philosophy, beliefs, religions, and collaboration within the community. Its social and cultural assets, resources, and environments are acknowledged by community members, based on self-reliance and mutual aids of the members, which contributes to the sustainable development of self-reliance in the community. Additionally, community members possess the idea to live with the forest, whilst benefiting from it. Therefore, Hom occupation contributes to the sustainable conservation of the forest. This corresponds to Grit Piriyatachagul et al. (2020), who stated that some of the local plants are not only local agricultural plants since the community possesses the local wisdom of agroforestry mixed cultivation, based on the idea to live with the forest whilst benefiting from it for the sustainable self-reliance of the members. The purposes of this idea are the food production and preservation of natural balance, in forms of systemic reliance.

2) Knowledge management of local wisdom Mohom for sustainable inheritance and lifelong learning: study results revealed that there are seven knowledge management processes in Ban Thung Hong community: 1) knowledge identification; 2) knowledge creation and acquisition; 3) knowledge organization; 4) knowledge codification and refinement; 5) knowledge access; 6) knowledge sharing; and 7) learning. This corresponds to the Office of the Public Sector Development Commission, and Thailand Productivity Institute (2005), which state that there are seven important steps of the learning management process which contribute to actions and sustainable self-reliance. Additionally, there exists Hom culture management in the community through its Mohom dyeing learning center, in which the community members have collaborated in the design of the inheritance process of Hom culture for collaborative self-reliance. They also respond to the needs of the community through "lifelong learning" which has been adapted to the context of the community regarding learning among the members, or between members and teenagers, which eventually lead to the development of learning places, travel destinations, and local database as the learning sources of the community. This corresponds to Charin Mangkhang et al. (2018) who stated that knowledge management process of the community for self-reliance through the participation of its member with the purpose to respond to its needs are generally non-systemic learning methods which are adapted to the context of the community regarding mutual learning, which in turn contributes to the development of learning sources and lifelong learning. It also corresponds to Bertets, cited in Ponthida Wichianpanya (2004), who stated that knowledge management is management to constantly create new knowledge foundations, which focuses on the collaborative operation and knowledge publication. Additionally, Ban Thung Hong people also intend to manage the knowledge of Mohom local wisdom as a learning center that provides access to the knowledge regarding the lifestyle and culture of the community, especially for local teenagers. This contributes to "Strong Citizens of Phrae" through learning management, free distribution of authority, and provision of educational opportunities, to promote equality for teenagers, good relationships within the community, and value of the local resources of the community. This corresponds to Peter F. Beyer (2003), who stated that the cultural study movement is a formation of the collaborative acquisition of culture, history, and tradition, of which the purpose is to change the idea of the members into "Citizens of the Society" rather than "Citizens of the Government". One of the important expectations of the community is to preserve the lifestyle pattern of Hom culture, despite the social changes from external sources which influence the role of the community. This corresponds to Natthawat Sutthiyothin (2013) who stated that cultural inheritance is a process of learning and development with the purpose to conserve the identity of the concepts, beliefs, lifestyle, and practices. The process of cultural inheritance is considered a "Dynamic" process, which circulates infinitely. 


\section{References}

Auaearoon, B. (2005). Construction of learning units on Mo Hom Sungmen local wisdom, Sungmenchanupatham School, Phrae educational service area 2. Chiang Mai: Chiang Mai University.

Beyer, P. F. (2003). Four Approaches to Globalization. In R. Robertson \& K. E. White (Eds.), Globalization: Critical Concepts in Sociology (vol. 1, pp. 155-181).

Chanawee et al. (2017). Inheritance of Songkran Cultural Heritages for Development of Education along the Thai-Cambodia Borders. Local Research Journal, 11(3), 95-109.

Chuan, P. (2004). Enhancement and Adaptation of Local Wisdom in Modern Age. San Phasa Thai., 3(3), 14-23.

Community Development Department. (2014). Manual of Knowledge Management of a Community (with Video CD). Bangkok: Division of Community Knowledge Management Promotion, Community Development Department.

Hubbard, \& Power. (1999). Living the questions: A guide for teacher-researchers. York, ME: Stenhouse.

Intezari, A., Taskin, N., \& Pauleen, D. J. (2017). Looking beyond knowledge sharing: An integrative approach to knowledge management culture. Journal of Knowledge Management, 21(2), 492-515. https://doi.org/10.1108/JKM-06-2016-0216

Kamonpon, P.-N. et al. (2009). Cultivation of Hom (Strobilanthes cusia (Nees) Kuntze) by Tissue Culture. Chiang Mai: Maejo University.

Lincoln, Y. S., \& Guba, E. G. (1985). Naturalistic inquiry. Beverly Hills, Calif: Sage Publications. https://doi.org/10.1016/0147-1767(85)90062-8

Mangkang, C. et al. (2019). Research report on King Bhumibol's science knowledge: Creative learning through Miang culture to promote green citizenship in different context areas in the northern of Thailand. Chiang Mai: Chiang Mai University.

Office of the Public Sector Development Commission, and Thailand Productivity Institute. (2005). Learning Management from Theories to the Practice. Bangkok: Office of the Public Sector Development Commission, and Thailand Productivity Institute.

Phuwanatwichit, T. (2015). Conceptual Framework of the Community Welfare Concept Based on Community Resources: Choices for Sustainable Community Self-Reliance. "MFU Connexion" Journal of Humanities and Social Sciences, 4(2), 65-94.

Piriyatachagul, G. (2020). The Cultural Transferring Process of Miang for Self-Reliance in Highland Communities. Chiang Mai: Chiang Mai University.

Piriyatachagul, G. et al. (2020a). Miang Culture: The Community Resources Management Through "Design-Based Learning" for Self-Reliance of Highland Communities in the Upper Northern Thailand. Higher Education Studies, 10(3), 63-71. https://doi.org/10.5539/hes.v10n3p63

Piriyatachagul, G. et al. (2020b). Miang Culture: The Community Resource Management for Self-Reliance of Highland Communities in Upper Northern Thailand. Asia Pacific Journal of Education, Arts and Sciences, 7(2), 97-107.

Ponthida, W. (2004). Knowledge Management. Bangkok: Thankamon Printing.

Putivoranat, M. et al. (2015). The Testing of Suitable Light Intensity to Growth of Strobilanthes cusia (Nees). In the Research Project Report on Research and and on Strobilanthes cusia (Nees) Kuntze Production in Phrae Province. Bangkok: Department of Agriculture.

Songleknok, S. et al. (2015). Knowledge Management Process of Indigo Dyed Cloth Community Business. KKU Research Journal (Graduate Studies), 15(3), 1-14.

Sutthiyothin, N. (2013). Successful cultural inheritance. Retrieved December 20, 2020, from http://nattawats.blogspot.com/2013/04/cultural-inheritance.html (in Thai).

\section{Copyrights}

Copyright for this article is retained by the author, with first publication rights granted to the journal.

This is an open-access article distributed under the terms and conditions of the Creative Commons Attribution license (http://creativecommons.org/licenses/by/4.0/). 